\title{
DNA analyses of a private collection of microbial green algae contribute to a better understanding of microbial diversity
}

Ryo Hoshina

\begin{abstract}
Background: DNA comparison is becoming the leading approach to the analysis of microbial diversity. For eukaryotes, the internal transcribed spacer 2 (ITS2) has emerged as a conspicuous molecule that is useful for distinguishing between species. Because of the small number of usable ITS data in GenBank, ITS2 sequence comparisons have only been used for limited taxa. However, major institutions with planktonic algal culture collections have now released small subunit (SSU) to ITS rDNA sequence data for their collections. This development has uplifted the level of molecular systematics for these algae.
\end{abstract}

Results: Forty-three strains of green algae isolated from German inland waters were investigated by using SSU-ITS rDNA sequencing. The strains were isolated through the direct plating method. Many of the strains went extinct during the years of culture. Thus, it could be expected that the surviving strains would be common, vigorous species. Nevertheless, 12 strains did not match any known species for which rDNA sequences had been determined. Furthermore, the identity of one strain was uncertain even at the genus level.

Conclusions: The aforementioned results show that long-forgotten and neglected collections may be of great significance in understanding microbial diversity, and that much work still needs to be done before the diversity of freshwater green algae can be fully described.

Keywords: Green algae, Internal transcribed spacer 2 (ITS2), Microbial diversity, Private collection, Species delimitation

\section{Background}

With the current rates of biodiversity loss, biodiversity conservation is receiving much attention. In many parts of the world, various animals and plants are being intensively studied, and conservation efforts for many species are well underway. Knowledge of microbial diversity, however, remains rudimentary. The current number of known microorganism species is a fraction of the diverse population of microorganisms [1,2]. Much research, particularly the identification and description of species, is still required before microorganism diversity can be accurately quantified.

The development of the microscope made it possible to observe organisms smaller than dust; and with modern technological advances, the field of microbiology, especially

Correspondence: wwhoseena@hotmail.com

Department of Bioscience, Nagahama Institute of Bio-Science and Technology, Tamura 1266, 526-0829 Nagahama, Shiga, Japan microorganism systematics, has blossomed. DNA research methods have now facilitated the development of an entirely new level of systematics, thereby redefining the species concept. In particular, studies on various types of microorganisms have led to the development of their systematics. New techniques have revealed that many separate species were originally mistakenly grouped together as single morphospecies. A well-known example of this is Chlorella, which are common algae in natural water bodies. They are composed of simple, green, spherical cells containing a minimal set of organelles: one nucleus, one chloroplast, and one mitochondrion. These algae were originally considered one species, but small subunit (SSU) rDNA phylogenies have since shown that the group is in fact polyphyletic, consisting of morphospecies in more than one class $[3,4]$. Based on the initial phylogenetic studies, Huss et al. [4] divided "true" Chlorella to four monophyletic species, including the type species Chlorella vulgaris. However, later studies identified some species that 
are morphologically different and draw their phylogenetic origins from the "true" Chlorella group e.g. [5-9].

The internal transcribed spacer 2 (ITS2) has emerged as a useful and conspicuous molecule for distinguishing between species. The ITS2 is located between $5.8 \mathrm{~S}$ rRNA and LSU rRNA, which plays an important role in processing events during rRNA maturation e.g. [10,11], and the secondary structures of ITS2 are highly conserved throughout the eukaryota [12]. The primary sequence of ITS2 region is highly conserved within species, but is highly divergent between species e.g. [13]. In general, the diversity of ITS2 sequence comparisons are either less than $2 \%$ or more than $10 \%$ (gaps are counted as a fifth character). This characteristic strongly encourages a species concept based on ITS2 sequence differences. Compensatory base changes (CBCs) in the ITS2 secondary structure also encourage species separation e.g. $[14,15]$. The presence of at least one CBC has been correlated with the separation of two species, which is classified here by using the biological species concept based on the production of fertile offspring [14]. This hypothesis has been supported by data on various eukaryotic groups, including plants, fungi, and animals ([15] and references therein). Species concepts based on ITS2 differences in chlorophytes have gained wide acceptance. They also serve as a key to identifying and describing true microorganism diversity. This development also reveals the possible pitfalls of classification based on morphological characteristics.

In recent years, molecular phylogeny has been increasingly applied to the floristic study of planktonic green algae e.g. [16-19]. However, these studies analyzed SSU rDNA only and avoided species-level designation. This may have been largely because of the small amount of usable ITS data available in GenBank. However, major institutions holding algal culture collections, the Culture Collection of Algae and Protozoa (CCAP, UK), and the National Institute for Environmental Studies (NIES, Japan), have now released SSU to ITS rDNA sequence data for their collections. This has led to unprecedented developments in molecular systematics. Making use of these data, I have investigated the laboratory's historical stocks of green algae, many of which have been neglected and forgotten about, which were isolated from German inland waters. Based on my findings, I discuss the potential of such archival lab stocks in supplementing our knowledge of biodiversity.

\section{Methods}

\section{Cultures}

Strains of green algae were established through simple methods. Water samples of several hundred microliters each were spread onto 1\% agar plates containing 20\% Gamborg's B5 basal medium with mineral organics
(Sigma-Aldrich, MO), to which was added 1/10 volume of lettuce juice medium [20] at $\mathrm{pH}$ 7.5. (The resulting medium is hereafter referred to as $1 / 5 \mathrm{GL}$ medium.) The plates were incubated for two or three weeks under illumination by a light-emitting diode (LED) lamp (12 h/ $12 \mathrm{~h}$ light/dark cycle) at $15^{\circ} \mathrm{C}$. Small single colonies (ca. $300 \mu \mathrm{m}$ ) that emerged were dissolved in water, and then spread onto a new plate under the same conditions. Single colonies that emerged from these cultures were transferred to liquid 1/5 GL medium (Table 1).

The established colonies were cultured on two different media: first $1 / 5 \mathrm{GL}, \mathrm{C}$ medium [21], and then $0.1 \%$ Hyponex (Hyponex, Osaka). They were maintained under LED illumination ( $12 \mathrm{~h} / 12 \mathrm{~h}$ light/dark cycle) at $10^{\circ} \mathrm{C}$. The strains are available from the author upon request.

The culture stocks were observed under an Olympus BX60 light microscope (Olympus, Tokyo), and images were obtained with an Olympus DP72 digital camera.

\section{DNA extraction, amplification, and sequencing}

DNA extractions using the DNeasy Plant Mini Kit (Qiagen, Düsseldorf, Germany) were performed. Polymerase chain reaction (PCR) was carried out to amplify SSU to ITS rDNA by using the primer pairs SR-1/SR-9 [22], SR-6 [22]/SR-12 k [23], INT-4 F [24]/ITS4 [25] and INT4 F/HLR-3R [23]. PCR products were purified with NucleoSpin Gel and PCR Clean-up (Macherey-Nagel, Düren, Germany), and were directly sequenced by using the Operon DNA sequencing service (Operon Biotechnology, Tokyo). Some strains were amplified and sequenced only their ITS rDNA locus.

\section{Phylogenetic analyses}

The SSU rDNA sequences were first checked for group I introns insertions (methods for group I intron ascertainment [26]). The joined exons were then submitted to the Basic Local Alignment Search Tool for Nucleotides (BLASTN, National Center for Biotechnology Information) for comparisons between sequences. Phylogenetic analyses of Chlorophyceae and Trebouxiophyceae were conducted separately. Taxon samplings for tree analyses were mainly based on recent papers [27-29]. The closest organisms for each strain that had been identified through BLASTN search were subsequently added. The SSU rDNA sequences were initially aligned automatically by using Clustal X2 software [30] and then aligned manually, taking into account secondary structure models for C. vulgaris [3] and Heterochlorella luteoviridis [31]. The $5^{\prime}$ and $3^{\prime}$ terminal regions were removed.

Two phylogenetic trees were constructed through the maximum likelihood (ML) method in PAUP $4.0 \mathrm{~b} 10$ (Sinauer Associates, MA) or MEGA5 [32], and the neighbor-joining (NJ) method in the Saitou and Nei 
Table 1 Strains sequenced in the study and their taxonomic designation

\begin{tabular}{|c|c|c|c|c|}
\hline \multirow[t]{2}{*}{ Strain } & \multicolumn{3}{|c|}{ rDNA sequence } & \multirow[t]{2}{*}{ Taxonomic designation } \\
\hline & Acc. no. & Coverage & SSU intron* & \\
\hline$\overline{\text { GB1a }}$ & AB917097 & SSU-ITS2 & & Desmodesmus sp. \\
\hline GB1C & AB917098 & SSU-ITS2 & & 'Ankistrodesmus' gracilis \\
\hline GB1d & AB917099 & SSU-ITS2 & & Pectinodesmus sp. \\
\hline GB1e & AB917100 & SSU-ITS2 & & Acutodesmus obliquus \\
\hline GB1g & AB917101 & SSU-ITS2 & & Acutodesmus obliquus \\
\hline GB1h & AB917102 & SSU-ITS2 & & Pectinodesmus sp. \\
\hline GB1j & AB917103 & SSU $-5^{\prime} L S U$ & 516 & Pectinodesmus sp. \\
\hline GB1k & AB917104, -105 & SSU $-5^{\prime} L S U$ & & Micractinium sp. \\
\hline GS2i & AB917106 & SSU-ITS2 & $516,943,1512$ & Desmodesmus brasiliensis \\
\hline GS2j & AB917107 & SSU-ITS2 & 516 & Desmodesmus opoliensis \\
\hline GS2k & AB917108 & 3'SSU-ITS2 & - & Desmodesmus opoliensis \\
\hline GS2L & AB917109 & SSU-ITS2 & $516,943,1512$ & Desmodesmus brasiliensis \\
\hline GS2m & AB917110 & SSU-ITS2 & 516 & Desmodesmus opoliensis \\
\hline GS2n & AB917111 & SSU-ITS2 & $516,943,1512$ & Desmodesmus brasiliensis \\
\hline GS2O & AB917112 & SSU-ITS2 & & Desmodesmus armatus \\
\hline GS2p & AB917113 & SSU-ITS2 & & Desmodesmus armatus \\
\hline GS3a & AB917114 & SSU-ITS2 & & Acutodesmus obliquus \\
\hline GS3b & AB917115 & $3^{\prime} S S U-5^{\prime} L S U$ & - & Acutodesmus obliquus \\
\hline GS3C & AB917116 & SSU-ITS2 & 943 & Tetranephris brasiliensis \\
\hline GS3d & AB917117 & $3^{\prime} S S U-5^{\prime} L S U$ & - & Acutodesmus obliquus \\
\hline GS3e & AB917118 & SSU-ITS2 & & Acutodesmus obliquus \\
\hline GS3f & AB917119 & SSU-ITS2 & 943 & Tetranephris brasiliensis \\
\hline GS3g & AB917120 & 3'SSU-5'LSU & - & Acutodesmus obliquus \\
\hline GS3h & AB917121 & 3'SSU-5'LSU & - & Acutodesmus obliquus \\
\hline GS3i & AB917122 & SSU-ITS2 & & Acutodesmus obliquus \\
\hline GS3j & AB917123 & 3'SSU-ITS2 & - & Tetranephris brasiliensis \\
\hline GS3k & AB917124 & $3^{\prime} S S U-5^{\prime} L S U$ & - & Acutodesmus obliquus \\
\hline GS3m & AB917125 & SSU-ITS2 & & Acutodesmus obliquus \\
\hline GS3n & AB917126 & SSU-ITS2 & & Acutodesmus obliquus \\
\hline GS3p & AB917127 & SSU-ITS2 & & Acutodesmus obliquus \\
\hline GM4a & AB917128 & SSU-5'LSU & & Desmodesmus sp. \\
\hline GM4b & AB917129 & SSU-5'LSU & 156, 943, 1046, 1139, 1512 & Selenastraceae sp. \\
\hline $\mathrm{GM} 4 \mathrm{C}$ & AB917130 & SSU-ITS2 & 516,1512 & Desmodesmus sp. \\
\hline GM4d & AB917131 & SSU $-5^{\prime} L S U$ & $516,943,1046$ & Nephrochlamys subsolitaria \\
\hline GM4e & AB917132 & SSU-5'LSU & $40,156,516,1046,1139,1512$ & Neochloris sp. \\
\hline $\mathrm{GM} 4 \mathrm{f}$ & AB917133 & SSU-ITS2 & & Desmodesmus armatus \\
\hline GM4g & AB917134 & SSU-ITS2 & $516,943,1512$ & Desmodesmus bicellularis \\
\hline GM4h & AB917135 & SSU-ITS2 & 516,943 & Desmodesmus armatus \\
\hline GM4i & AB917136 & SSU $-5^{\prime} L S U$ & 516 & Desmodesmus sp. \\
\hline GM4j & AB917137 & SSU-5'LSU & 516,1512 & Desmodesmus sp. \\
\hline GM4k & AB917138 & SSU-5'LSU & & Desmodesmus armatus \\
\hline GM4n & AB917139 & SSU-5'LSU & & Desmodesmus pannonicus \\
\hline GA5a & AB917140 & SSU-5'LSU & & Coccomyxa sp. \\
\hline
\end{tabular}

*Insertion position corresponding to Escherichia coli rRNA gene.

Strain names indicate the water source in Germany from which the strain originated. GB1: a pond in the Botanischer Garten, Berlin, July 28, 2011; GS2: an artificial pond in the Mittlerer Schlossgarten, Stuttgart, July 31; GS3: a fountain in the Oberer Schlossgarten, Stuttgart, July 31; GM4: an artificial pond in Denninger Anger Park, Munich, Aug. 1; GA5: Alpsee Lake in the Ostallgäu district of Bavaria, Aug. 2. 
model in Clustal X2. The best-fit evolutionary models were identified by using Modeltest 3.7 [33] or MEGA5. By utilizing the results to derive the settings, a heuristic search using the NJ tree as the starting tree and a nearest-neighbor interchange swapping algorithm was performed. Bootstrap probabilities were computed for 100 (ML) and 1000 (NJ) replicates.

For advanced analyses at the genus or species level, phylogenetic analyses using both NJ and ML methods were conducted by examining ITS2 or SSU-ITS rDNA in conjunction with the results of recent studies of several different groups of species (Scenedesmus-related species: [34], Desmodesmus: [35], Chlorellaceae: [36]). ITS2 sequences were folded by using Mfold [37], and the secondary structures were used to aid manual alignment of those sequences and to check the presence/ absence of CBC. For each tree, identical sequences were treated as one operational taxonomic unit.

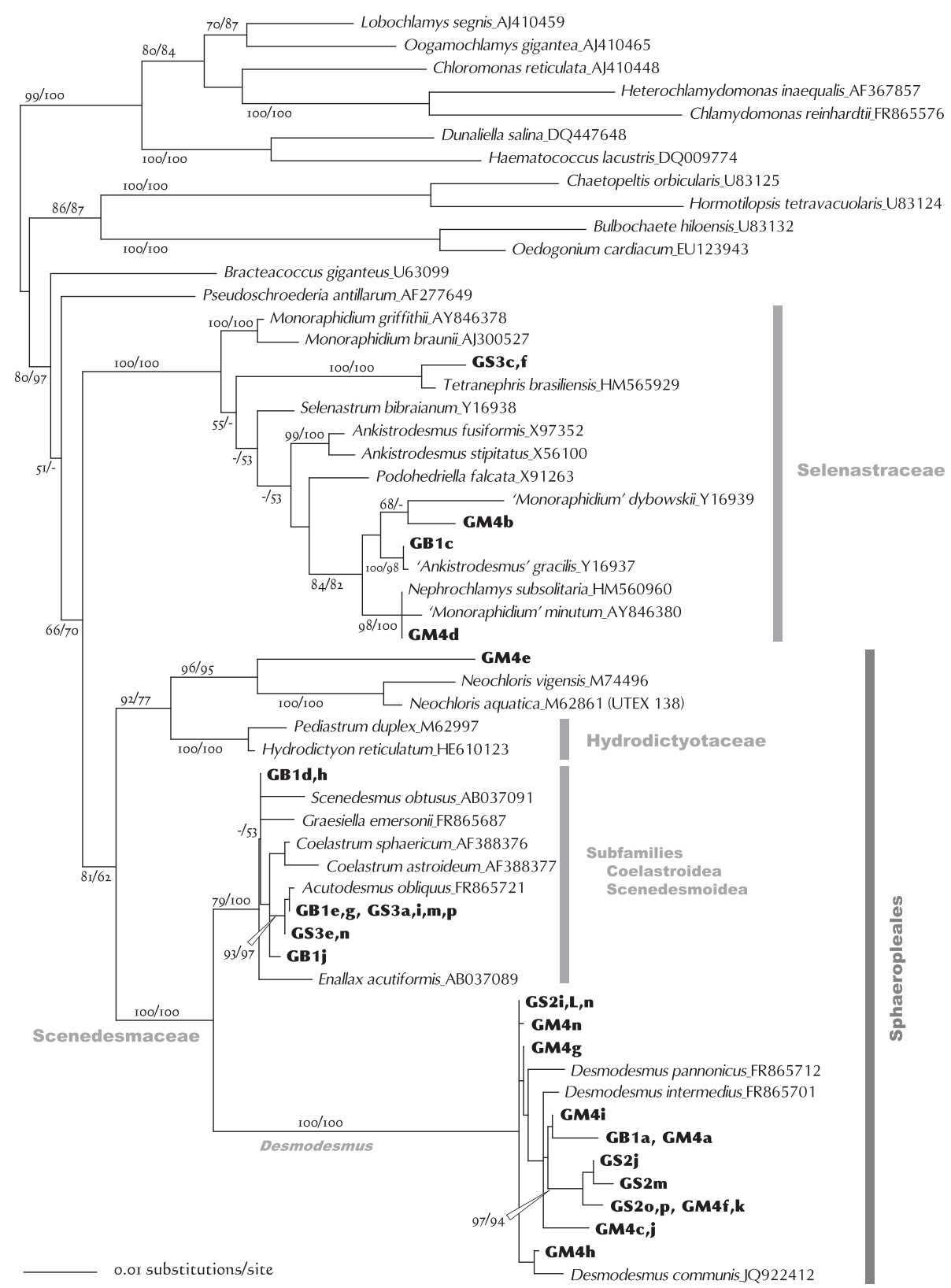

Figure 1 Unrooted phylogenetic tree for Chlorophyceae based on SSU rDNA gene sequences (length $1605 \mathrm{nt}$ ). Algal strains analyzed in this study were indicated by alphanumeric codes in bold. This tree was constructed by using the maximum likelihood (ML) method under the GTR $+I+G$ evolutionary model. Numbers at each node represent bootstrap probabilities from ML/NJ analyses; only values above $50 \%$ are shown. 

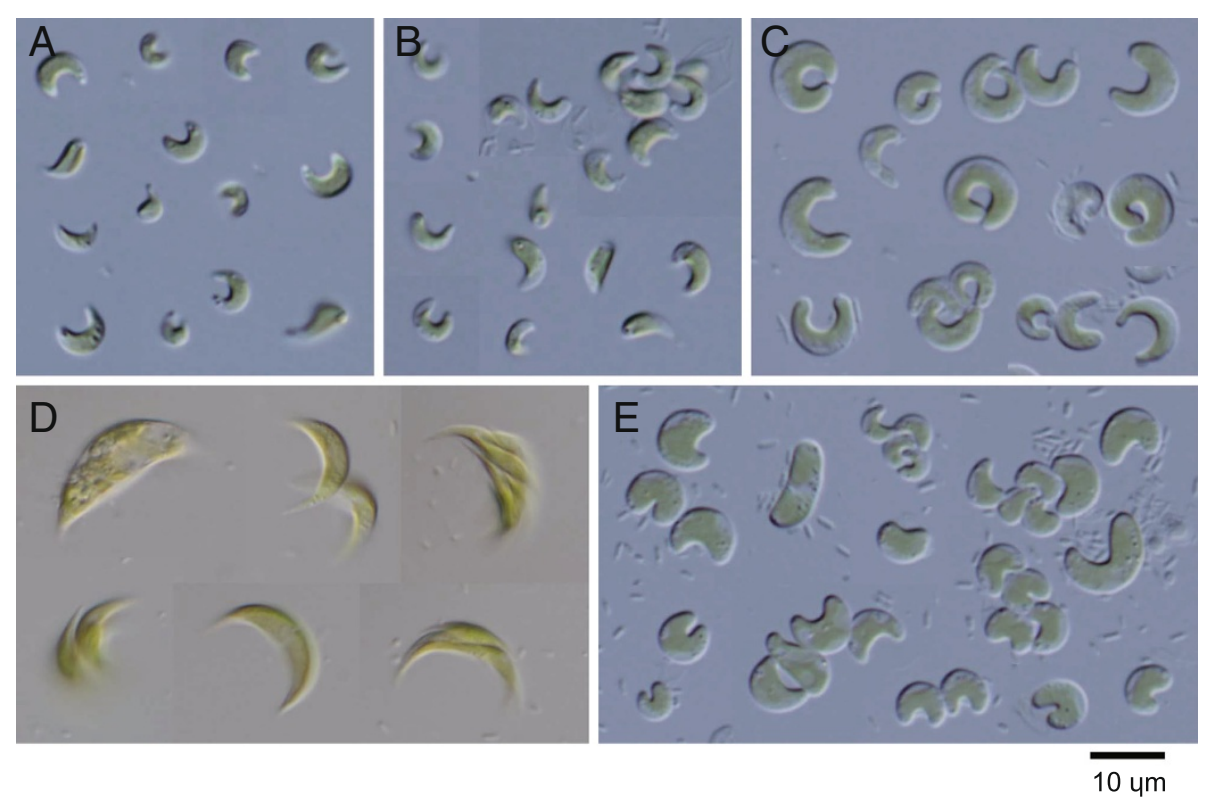

Figure 2 Light microscopy images of algal strains identified as members of Selenastraceae from a private collection. Strains were collected from German inland waters and were named according to their source (Table 1). A: GS3C, B: GS3f, C: GM4b, D: GB1c, E: GM4d.

\section{Results and Discussion}

BLASTN analyses indicated that all strains analyzed in this study belonged to either Chlorophyceae or Trebouxiophyceae. These two classes were therefore treated separately.

\section{Chlorophyceans}

The SSU rDNA tree for members of Chlorophyceae separated them into three broad groups: Selenastraceae, the Neochloris-Hydrodictyotaceae clade, and Scenedesmaceae (Figure 1).

Five strains (GB1c, GS3c and -f, and GM4b and -d) were included in the Selenastraceae clade (Figure 1). Phylogenetic relationships for this group were constructed based on SSU rDNA analysis [28,38,39], which indicated that some genera were polyphyletic. However, many strains remained inadequately treated. Lacking data for more rapidly evolving molecules for this group, such as ITS, necessitated the use of the SSU rDNA phylogeny to determine the relationships between the cultured strains and previously analyzed members of this group.

GS3c and -f were grouped with Tetranephris brasiliensis, the type species for Tetranephris. There are three Tetranephris SSU rDNA sequences in GenBank (HM483517, HM565927, and HM565929), all of which are from T. brasiliensis. GS3c and -f are closest to the sequence HM565927, and have only one transition in 1601 aligned sites (data not shown). Light microscopy revealed solitary, crescentshaped cells containing some granules (Figure 2A and B), which agrees with the morphological characteristic of T. brasiliensis and thus confirms that GS3c and -f are
T. brasiliensis strains. Furthermore, the strain GS3j, which was analyzed by ITS sequencing only, had an ITS sequence and morphology identical to that of GS3c and -f (Table 1).

GM4b was grouped with Monoraphidium dybowskii in the ML tree (Figure 1), but this was not supported by the NJ analyses. Of note, however, was that the type species of Monoraphidium, Monoraphidium griffithii, was placed in a different group in this family. GM4b cells ranged from horseshoe- to donut-shaped ( $M$. dybowskii cells are rhomboidal to labiate), with the diameters of

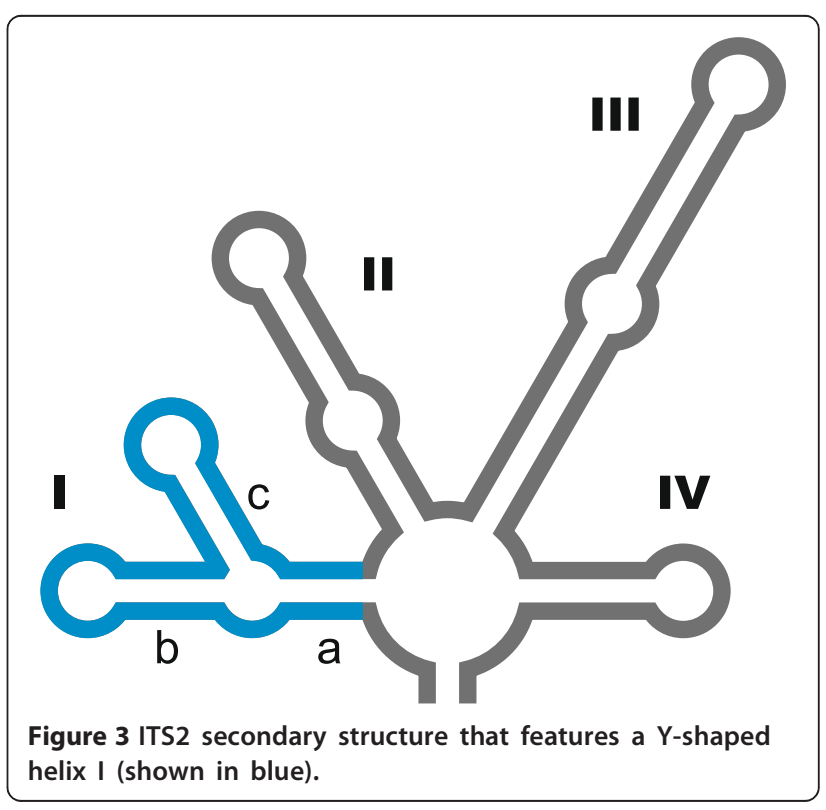




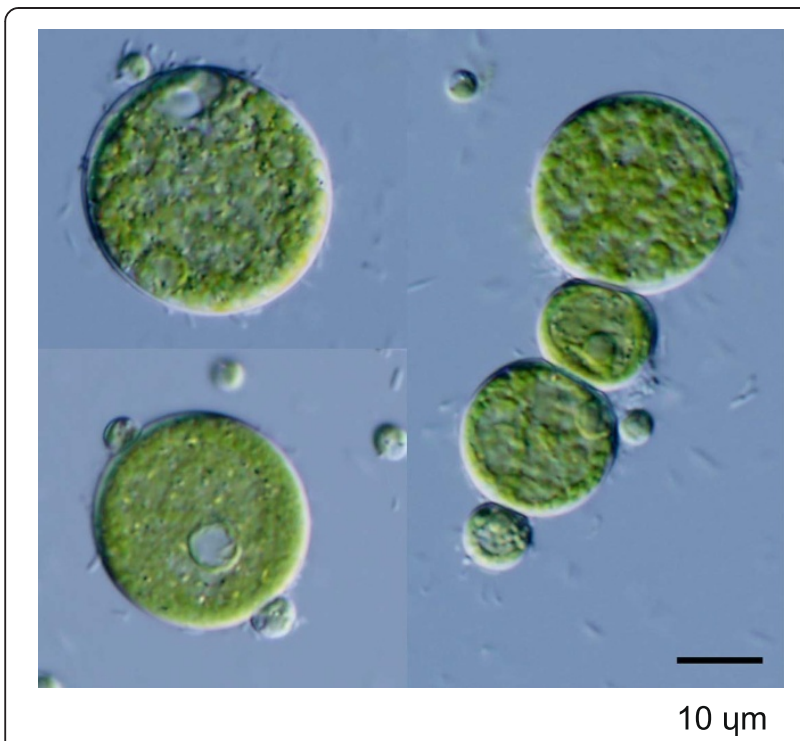

Figure 4 Light microscopy image of cells from strain GM4e of a private collection. This strain was collected from German inland waters and was named according to its source (Table 1).

the thickest parts between 2.5 and $4.0 \mu \mathrm{m}$ (Figure 2C). Therefore, GM4b could not be identified even to genus level at this stage.

GB1c was clustered with Ankistrodesmus gracilis (Figure 1). Notably, the type species of Ankistrodesmus, Ankistrodesmus fusiformis, was placed in a different group in this family.
GB1c cells were mainly crescent-shaped, 16-32 $\mu \mathrm{m}$ long, and 4-9 $\mu \mathrm{m}$ wide (Figure 2D). These morphocharacters are slightly different from that typical of $A$. gracilis (colony formation of 8-32 narrower crescent cells). As only one transition out of 1682 aligned sites between GB1c and A. gracilis was observed, GB1c was tentatively designated as a strain of $A$. gracilis.

GM4d was clustered with Nephrochlamys subsolitaria and Monoraphidium minutum (Figure 1). The GM4d sequence differed from that of $N$. subsolitaria by only two indels, and from that of $M$. minutum by five indels and four or five substitutions. The shape of GM4d cells resembled beans or curved cylinders (Figure 2E), similar to those of N. subsolitaria and M. minutum. Despite the pending taxonomic status of $M$. minutum, GM4d could be tentatively designated as a strain of $N$. subsolitaria.

GM4e was grouped with the Neochloris species, and the Pediastrum-Hydrodictyon clade (Hydrodictyotaceae) was identified as a sister group to this clade (Figure 1). A close relationship between Neochloris and the Hydrodictyotaceae has been reported many times e.g. [40], and they have been classified as Sphaeropleales. This group includes Scenedesmaceae [41]. Neochloris aquatica, the type species of this genus, has been described based on UTEX 138 (the culture held at The Culture Collection of Algae, University of Texas) and on CCAP 254/5. However, their SSU rDNA sequences differ considerably from each other. When the ITS2 sequence of GM4e was

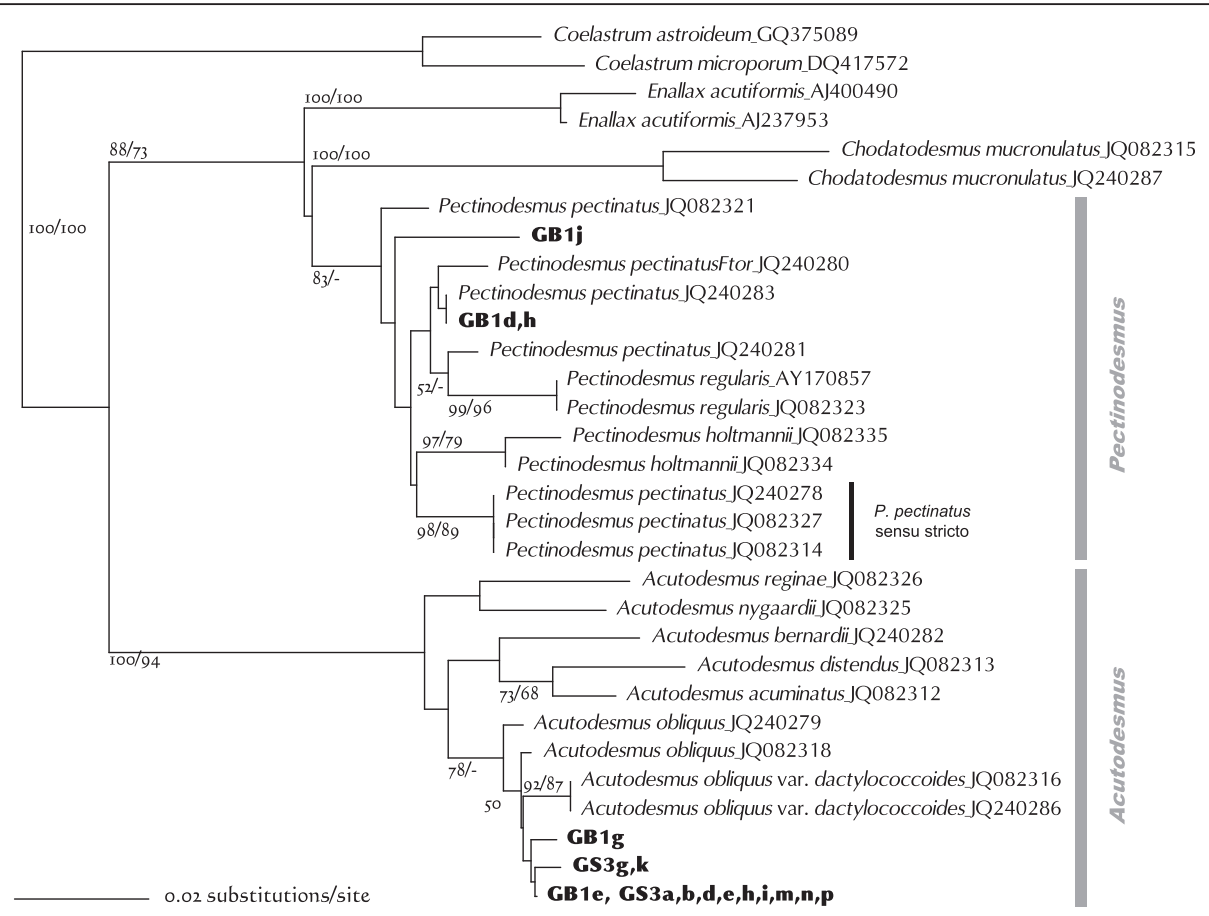

Figure $\mathbf{5}$ Neighbor-joining tree inferred from ITS2 sequence comparisons (length $\mathbf{2 8 3} \mathbf{n t}$ ). The Coelastrum species were used to root this tree. Numbers at each node represent bootstrap probabilities from NJ/ML (GTR + G model) analyses; only values above 50\% are shown. 
submitted to BLASTN, it showed almost $90 \%$ similarity to the UTEX 138 strain of N. aquatica, AY577764, which includes 5.8S-ITS2 rDNA [42]. However, it was completely different from the CCAP 254/5 sequence (FR865697, including SSU-ITS2 rDNA). Preliminary analysis of the ITS2 secondary structure showed that both GM4e and N. aquatica UTEX 138 have a Y-shaped helix I (Figure 3), similar to that of Sphaeropleales [43-45]. When the CCAP 254/5 sequence was submitted to BLASTN, it showed more than $99 \%$ similarities (including ITSs) to several strains of Chlorella vulgaris (Trebouxiophyceae). It is possible, therefore, that the CCAP 254/5 strain had been confused with another strain.

Light microscopy revealed small to large spherical cells $(3.2-32 \mu \mathrm{m})$ with a parietal chloroplast including one or more pronounced granules (Figure 4). Some cells contained segmentalized aggregations, which could be the development stage of zoospores. There is therefore no reason to exclude GM4e from Neochloris. AlgaeBase (http://www.algaebase.org) lists Neochloris as the taxonomically accepted genus name for eight species. Therefore, GM4e was designated as a species of Neochloris, although further comparative research with the other Neochloris species is required before this can be confirmed.

GM4e was particularly intron-rich; it contained six group I introns at S40, S156, S516, S1046, S1139, and S1512 (Table 1), which elongated its SSU rDNA to $4.3 \mathrm{~kb}$. This ties with Selenastrum capricornutum [46] for the most intron insertions in the SSU rDNA. In contrast, previously described Neochloris species do not have any introns. Descriptions of these introns will be published elsewhere.

The remaining strains identified as Chrolophyceans all belonged to Scenedesmaceae, within which they were clearly separated into two clades, namely, CoelastroideaScenedesmoideae and Desmodesmus [47] (Figure 1).

The Scenedesmus-related species were recently reanalyzed by using molecular phylogenetic techniques and electron microscopy e.g. [34,47], which generated several new genera and many new species. Strains GB1j, -d, and -h were grouped with one of the new genera, Pectinodesmus, in the ITS2 analyses (Figure 5). All three strains formed four-cell coenobia comprising spindle cells (Figure 6A-C). This morphology coincides with that of Pectinodesmus, but it is insufficient for clear delineation of species in this


Figure 6 Light microscope images of algal strains identified as members of Scenedesmus sensu lato. Strains were collected from German inland waters and were named according to their source (Table 1). A: GB1j, B: GB1d, C: GB1h, D: GB1g, E: GS3g, F: GS3k, G: GB1e, H: GS3a, I: GS3b, J: GS3d, K: GS3h. 
genus [34]. Pectinodesmus regularis has been recognized as an independent species, but its genetic differences from other species are tenuous [34]. Furthermore, many genetically distinct strains dispersed throughout this clade are tentatively treated as Pectinodesmus pectinatus (Figure 5), obfuscating the distinction between species. Comparison of the ITS2 structures reveal that GB1j has one $\mathrm{CBC}$ and two hemi-CBCs (a compensatory base change on only one side of a pairing, the next-best "proof" of a $\mathrm{CBC}$ ), and that GB1d and -h have one $\mathrm{CBC}$ when compared with $P$. pectinatus sensu stricto. Identification of strains GB1j, -d, and $-\mathrm{h}$ at species level must therefore be suspended until the phylogeny of the Pectinodesmus species becomes clear.

Thirteen strains (GB1e, -g, GS3a, -b, -d, -e, -g, -h, -i, -k, $-\mathrm{m},-\mathrm{n}$, and -p) were clustered with known Acutodesmus
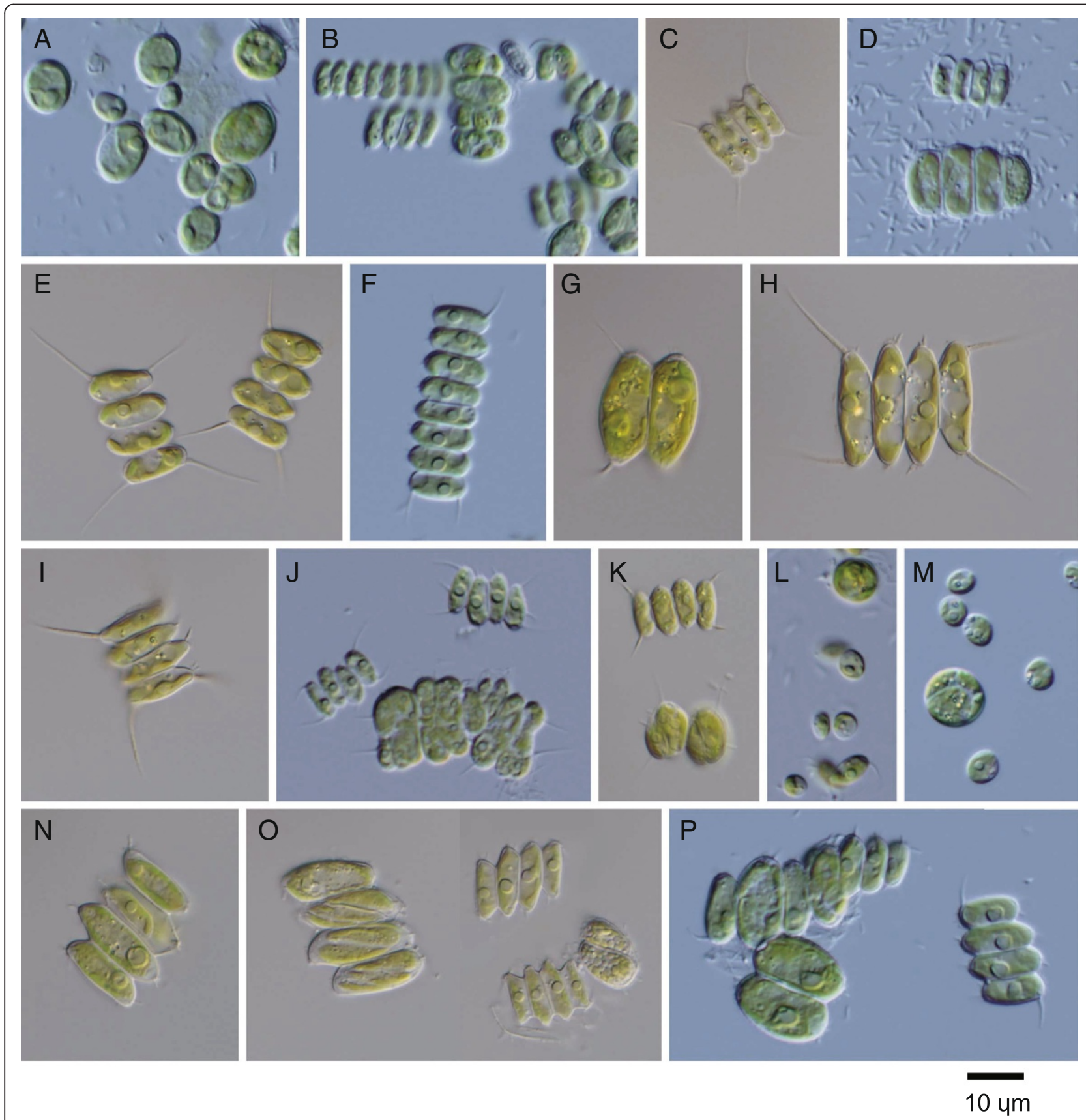

Figure 7 Light microscope images of algal strains identified as Desmodesmus species from a private collection. Strains were collected from German inland waters and were named according to their source (Table 1). A: GM4g, B: GM4i, C: GS2O, D: GM4h, E: GS2p, F: GM4k, G: GS2j, H: GS2k, I: GS2m, J: GM4a, K: GB1a, L: GM4c, M: GM4j, N: GS2i, O: GS2L, P: GM4n. 
obliquus strains (Figure 5). These culture strains had single- to eight-cell coenobia, and most cells were shorter and wider than those of typical A. obliquus strains (Figure 6D-K). This morphology could be related to the medium in which they were cultured. As CBC of these strains has not been found upon comparison with $A$. obliquus strains, they could be identified as A. obliquus.

Fawley et al. [16] suggested that a difference of even a single nucleotide in the SSU rDNA sequence could distinguish between species. However, this does not appear to be the case. Some strains with different SSU rDNA sequences had identical ITS sequences. For instance, there was one transition between the SSU rDNA sequences of GB1e and GS3e, but no substitutions in their ITS sequences.
Seventeen strains were included in the Desmodesmus genus (Figure 1). Most of these strains had typical Desmodesmus forms, i.e., four- or eight-celled coenobia with or without spines on the terminal cells (Figure 7). Species of this genus have been characterized based on cell-shape, spines, and cell-wall appendages. However, several species could not be unambiguously distinguished even by scanning electron microscopy. As a result, recent studies have used molecular comparisons e.g. [48-50].

Based on the ITS2 analyses, GM4g was clustered with Desmodesmus bicellularis strains (Figure 8). However, GM4g comprised single ellipsoids 5.1-15 $\mu \mathrm{m}$ long without any spines (Figure 7A), whereas D. bicellularis formed two- to eight-celled coenobia. Furthermore, Johnson et al. [48] observed irregularly shaped D. bicellularis cells with spine-like appendages (DQ417558). Because

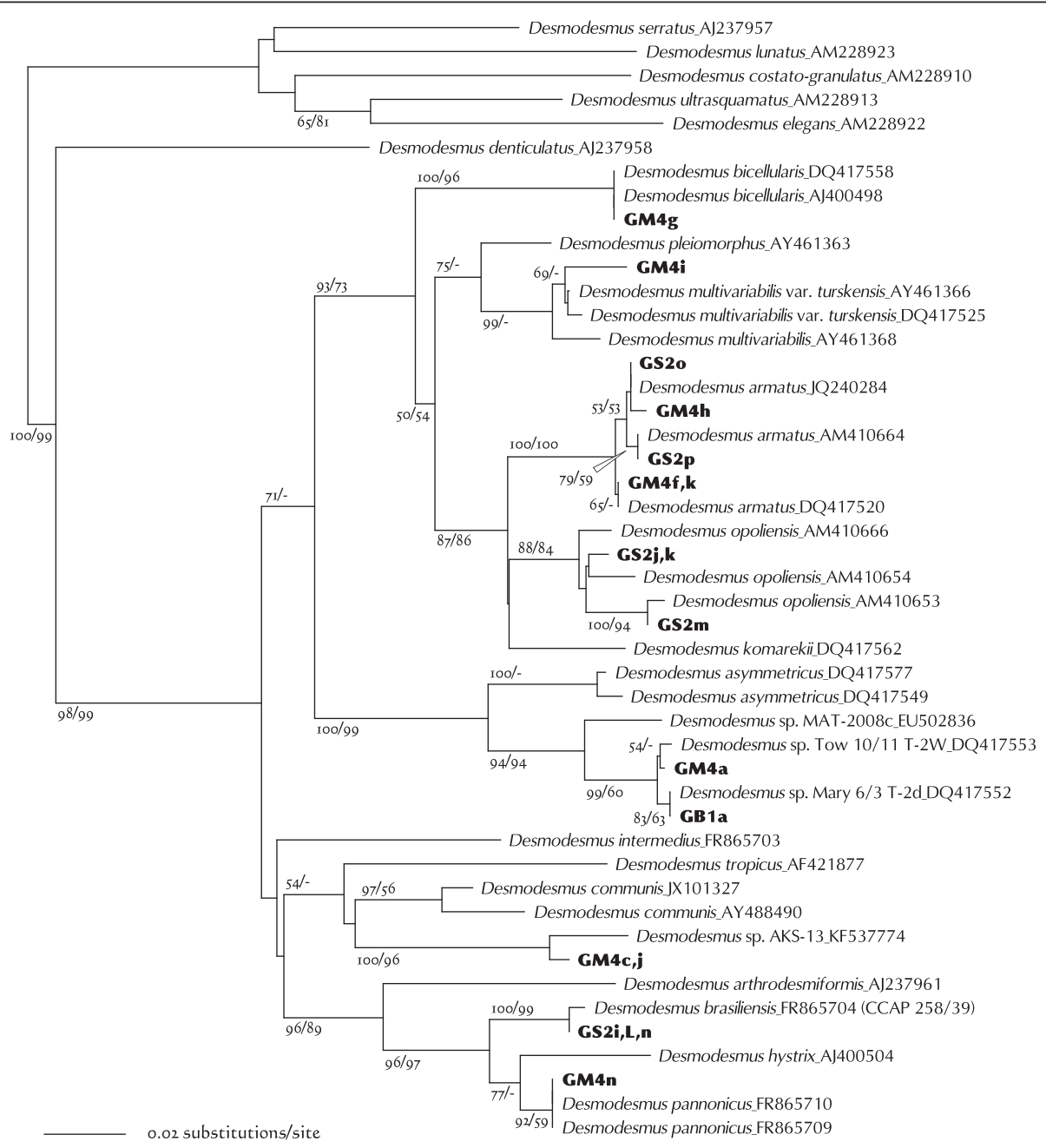

Figure 8 Neighbor-joining tree inferred from ITS2 sequence comparisons (length, $276 \mathbf{n t}$ ). Desmodesmus serratus, D. lunatus, D. costato-granulatus, D. ultrasquamata, and D. elegans were used to root this tree. Numbers at each node represent bootstrap probabilities from NJ/ML (SYM + I G model) analyses; only values above $50 \%$ are shown. 
the GM4g ITS2 sequence was $100 \%$ identical to that of $D$. bicellularis strains, GM4g is probably a different morphological form of $D$. bicellularis.

GM4i formed four- or eight-cell coenobia. Although this morphology is not clearly shown in Figure $7 \mathrm{~B}$, each cell had a few small spines at the longitudinal ends. GM4i was clustered with Desmodesmus multivariabilis strains (Figure 8); however, it had a CBC at helix Ib when compared with these strains. Species-level identification is therefore not yet possible.

The strains GS2o, -p, GM4f, - $\mathrm{h}$ and -k were clustered with Desmodesmus armatus strains (Figure 8). They formed four- or eight-cell coenobia with long spines at the apices of the terminal cells, but the spines of GM4h were less obvious (Figure 7C-F). Based on the ITS2 phylogeny and the absence of $\mathrm{CBC}$ between these five and the previously identified $D$. armatus strains, they could be designated as $D$. armatus strains.

GS2j, -k, and -m were clustered with Desmodesmus opoliensis strains (Figure 8 ). In this study, the three $D$. opoliensis strains were employed from GenBank. Although these D. opoliensis ITS2 discrepancies are minor (5-7 changes out of 253 aligned sites), there is a CBC at helix IV and hemi-CBCs at helices Ic, II, and IV among them. Each of the variable sites found in the GS2j, $-\mathrm{k}$, and $-\mathrm{m}$ strains applies to any of such variation. Their morphologies (two- or four-cell coenobia with long spines at the apices of terminal cells; Figure 7G-I) match those of the previously identified $D$. opoliensis strains. Therefore, they were tentatively identified as $D$. opoliensis strains.

GB1a and GM4a were placed in a clade comprising asyet unidentified species, which is somewhat independent from previously described species of a sister clade to Desmodesmus asymmetricus (Figure 8). There was no CBC between GB1a, GM4a, and the two nameless strains Tow 10/11 T-2 W and Mary 6/3 T-2d, which were collected from Minnesota, USA [16]. They were all clearly separated from MAT-2008c by two CBCs and two hemi-CBCs. GB1a and GM4a formed two-, four- or eight-celled coenobia, of which each cell had a few spines (Figure 7J and K). Cells were comparatively small $(3-6 \times 8-13 \mu \mathrm{m})$.

Based on the ITS2 sequences, GM4c and -j were separated from the other Desmodesmus species. Tree analyses showed that their closest taxon was Desmodesmus sp. AKS-13 (Figure 8), but they were distinguished from each other by two hemi-CBCs at helices II and III. GM4c and -j cells were nearly spherical (3.5-10.5 $\mu \mathrm{m})$, but some were ellipsoidal (up to $5.5 \times 8 \mu \mathrm{m}$; Figure 7L and M).

GS2i, - L, and -n formed two- or four-cell coenobia (Figure $7 \mathrm{~N}$ and $\mathrm{O}$ ). Each cell had a few short spines, and

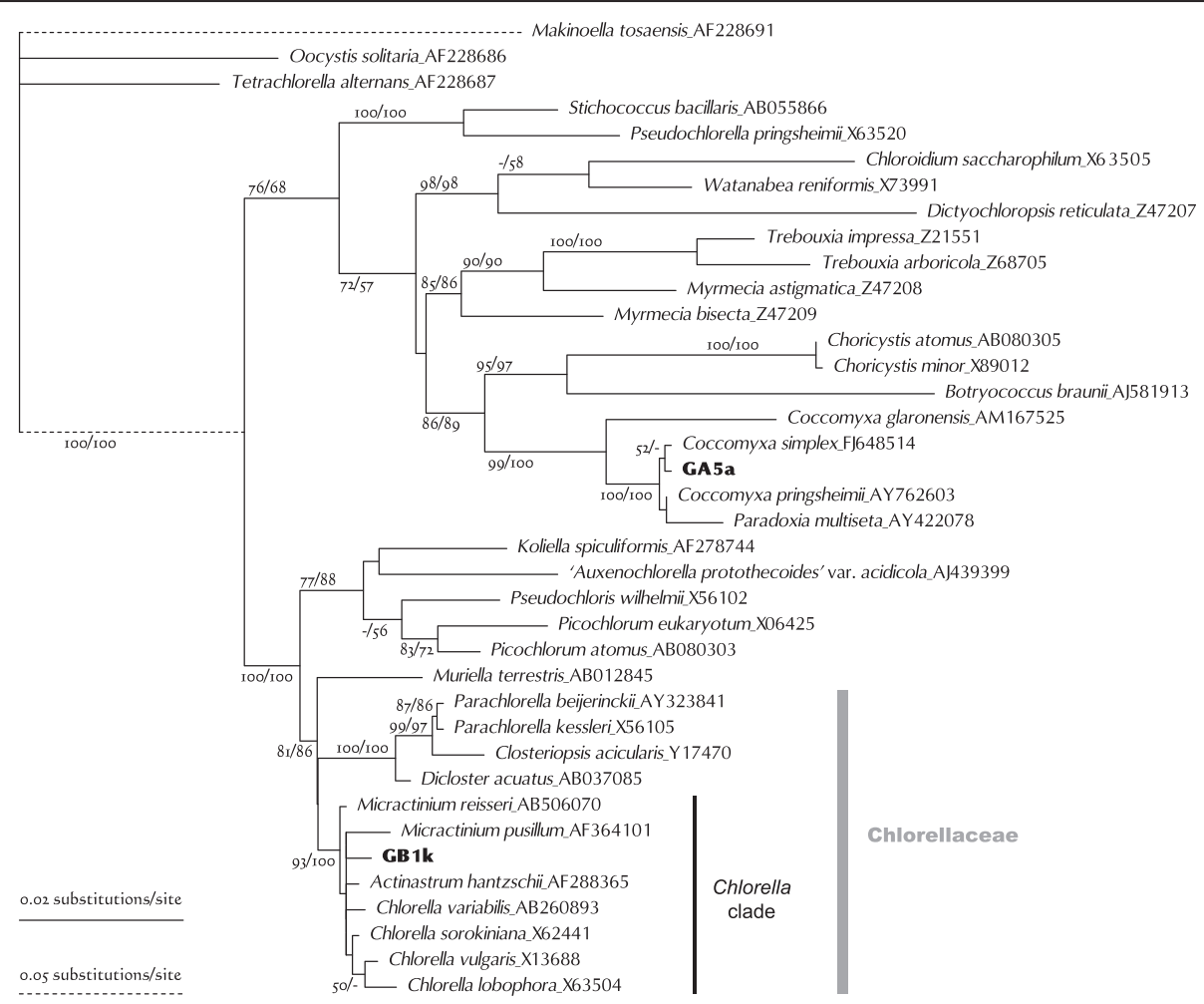

Figure 9 Phylogenetic tree for Trebouxiophyceae inferred based on SSU rDNA gene sequences (length $1624 \mathrm{nt}$ ). Algal strains analyzed in this study were indicated by alphanumeric codes in bold. This tree was rooted with Makinoella, Oocystis, and Tetrachlorella and was constructed by using the maximum likelihood (ML) method under the TN93 $+1+G$ evolutionary model. Numbers at each node represent bootstrap probabilities from ML/NJ analyses; only values above $50 \%$ are shown. 


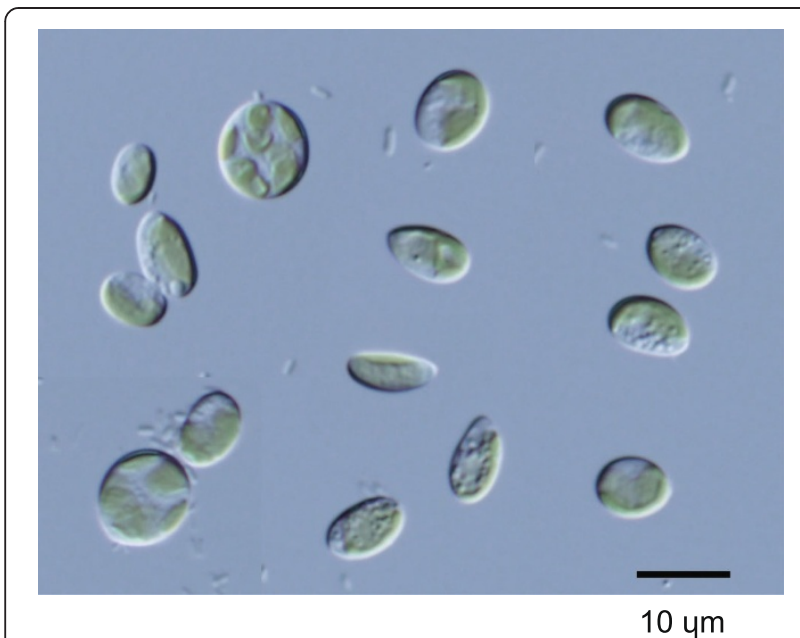

Figure 10 Light microscopy image of the GA5a algal strain from a private collection. This strain was collected from German inland waters and was named according to its source (Table 1).

some cells had granulated protoplasm. They were clustered with Desmodesmus brasiliensis CCAP 258/39 (Figure 8), with which there was no variation except for an $\mathrm{N}$ residue in the CCAP 258/39 sequence. CCAP has released five sequences (all including ITS2) for D. brasiliensis cultures. The ITS2 sequences of GS2i, -L, and -n closely matched the CCAP 258/39 sequence, but did not match the other four strains as closely (CCAP 258/40, 258/42, 258/43, and 258/44; these sequences were not used in this study). $D$. brasiliensis therefore contains several genetically distinct species. Because the authentic strain of $D$. brasiliensis has not yet been determined, I tentatively designate these three as strains of $D$. brasiliensis.

GM4n formed two- or four-cell coenobia or occurred as single cells (Figure 7P). Each cell had some spines, which projected in various directions. The ITS2 sequence for this strain was completely consistent with those of the $D$. pannonicus strains (Figure 8), so I designate GM4n as a strain of this species.

\section{Trebouxiophyceans}

Of the 43 strains of green algae that were analyzed in this study, only two were from Trebouxiophyceae.

Strain GA5a was clustered with Coccomyxa and Paradoxia species (Figure 9). These genera have been treated incertae sedis within the Trebouxiophyceae [51], and have not yet been revisited in detail by using molecular phylogenetic techniques. GA5a cells were simple ellipsoids, $7.0-11 \mu \mathrm{m}$ long and $4.2-8.0 \mu \mathrm{m}$ wide (Figure 10). They contained a girdle-shaped chloroplast without a visible pyrenoid. This morphology matches that of Coccomyxa or of the species classified hitherto as Pseudococcomyxa (shown as Coccomyxa simplex in Figures 9 and 11). BLASTN search for the GA5a ITS2 sequence found matches with several sequences. The GA5a sequence was identical to that of Choricystis sp. GSE4G (HE586518) (Figure 11). This was the case for both the ITS2 and the SSU-ITS rDNA. HE586518 was identified not as Coccomyxa or Paradoxia but as Choricystis. The morphology of Paradoxia was completely dissimilar to that of GA5a. In contrast, Coccomyxa and Choricystis have somewhat similar ellipsoidal single cells. However, Choricystis is a phylogenetically distinct genus, separate from Coccomyxa (Figure 9). Unfortunately, the authors who registered HE586518 have not yet published any information about this strain. For this reason, although GA5a is probably the same species as Choricystis sp. GSE4G, it may have to be designated as Coccomyxa sp. until publication of its further details.

Strain GB1k was included in the so-called "Chlorella clade" in Chlorellaceae (Figure 9). Members of this clade have been well studied, and recent studies have laid out guidelines for its genera and species delimitations [7,36,52-57]. GB1k was grouped with Micractinium in the SSU-ITS rDNA tree (Figure 12). This clade was

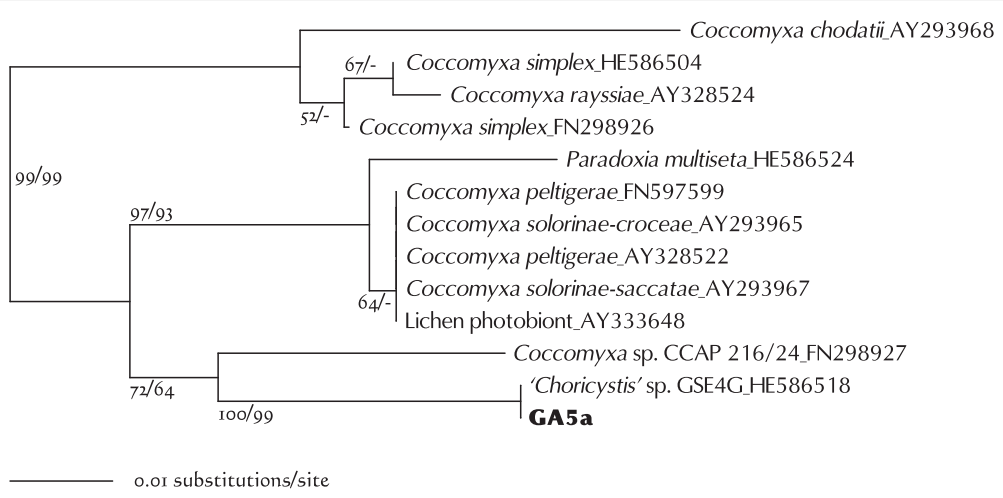

Figure 11 Neighbor-joining tree inferred from ITS2 (helices I- III) sequence comparisons (length $194 \mathrm{nt}$ ). Numbers at each node represent bootstrap probabilities from NJ/ML (GTR + I G model) analyses; only values above $50 \%$ are shown. 




Figure 12 Maximum likelihood tree constructed from SSU-ITS rDNA sequences (length $\mathbf{2 4 8 7} \mathbf{n t}$ ). Hegewaldia parvula was used to root this tree, which was constructed by using the GTR $+I+G$ evolutionary model. Numbers at each node represent bootstrap probabilities from ML/NJ analyses; only values above $50 \%$ are shown.

independent of other clades, and had a long node and overall higher bootstraps. GB1k comprised spherical cells $(4.5-8.5 \mu \mathrm{m})$ with a cup-shaped chloroplast containing a pyrenoid. Single cells were rare, and most cells formed coenobia (Figure 13). Micractinium is essentially a colonial species with several spines. However, recent studies have suggested that such morphological characteristics are

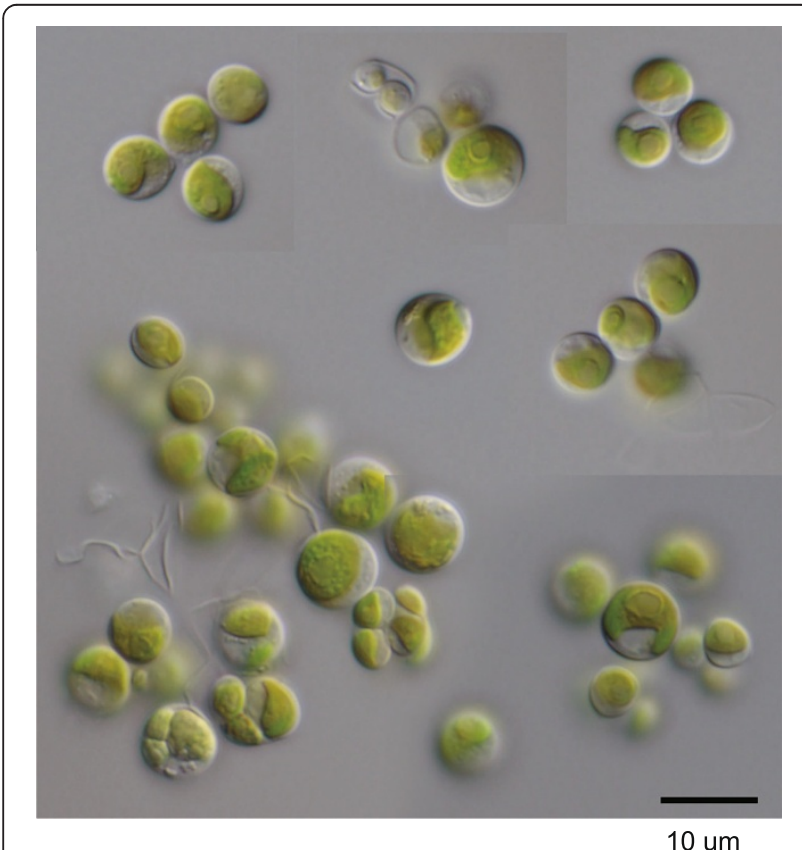

Figure 13 Light microscopy image of the GB1k algal strain from a private collection. This strain was collected from German inland waters and was named according to its source (Table 1). unsuitable for defining genera within Chlorellaceae e.g. [52,56]. In this regard, Luo et al. [56] instead examined the non-homoplasious synapomorphic molecular signature of the SSU rDNA or ITS2 sequence for the genus as well as its phylogenetic relationship. The only intelligible signature of Micractinium is C-G pairing at the tip of ITS2 helix III, which was found in GB1k (Figure 14). In ITS2 sequence comparisons, differences between GB1k and any other Micractinium species reached at least $25 \%$ (with gaps counted as fifth character). Although these large differences affect lengths or structures of helices and prevent accurate counting of $\mathrm{CBC}$, there were at least two CBCs between GB1k and any other Micractinium species. Because the genus Micractinium is characterized by a colonial species with several spines, only two Micractinium species are described as having spherical cells (Micractinium reisseri and Micractinium inermum). GB1k is therefore probably a nondescript species of Micractinium.

\section{Conclusions}

Many microbiology laboratories have vast microbial stocks isolated from natural environments. Some may have been collected as part of a search for new enzymes, antibiotics, or other applications. However, these stocks are often carelessly treated after the study has been completed, and are generally lost thereafter. My laboratory similarly owns large green algal stocks collected from natural water sources in various places. However, the number of culture stocks has been decreasing over time. There are numerous probable causes for this, including changes in the culture medium or other culture conditions, unexpected desiccation, and changes in culture management. If these stocks are likely to contain some 


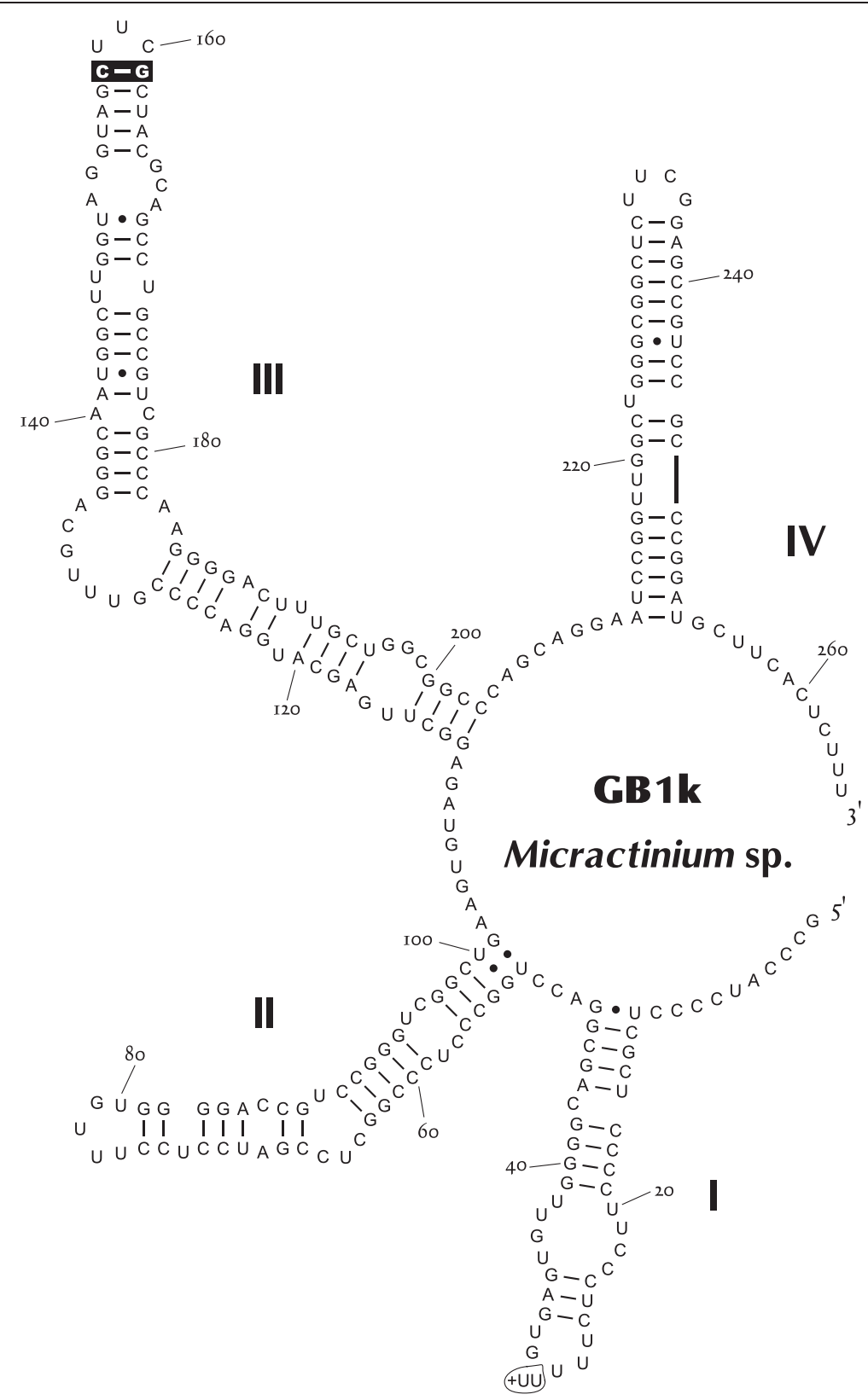

Figure 14 Predicted ITS2 secondary structure diagram for GB1k. The synapomorphic signature of genus Micractinium [56] is highlighted. The signature (+UU) at the terminal loop of helix I indicates the polymorphism (indels) in the GB1k genome.

interesting species, then it may be better to donate the strains to culture collection institutions, rather than to keep them for no reason. The present study focused on a private collection isolated from German inland waters, and examined their distinctiveness as a preliminary step toward donating the strains to a public collection. The method of establishing strains was very simple (q.v. Methods). This method may have selected only the species with the ability to grow faster and resistance to minor desiccation. Species that grow slowly or are unable to colonize an agar plate would be excluded from the selection. In addition, culture stocks have gone through a change in culture media, and some morphologically characteristic strains have already died out. That is, the culture stocks considered here are likely to be common and very vigorous species. Nevertheless, 12 strains out of 43 did not match any known species of which rDNA sequences have been determined (Table 1). One strain was nondescript even at the genus level. This fact suggests that the true diversity 
of freshwater green algae is still a long way from being fully described, and that even small laboratory stocks can contribute to our understanding of the diversity of microorganisms. I sincerely hope that this study prompts all researchers around the world to examine private microbial stocks and to publish their results.

There is intense debate about the diversity and distribution of eukaryotic microorganisms. One argument suggests that there is a limited number of species and that most of them are global in distribution e.g. [58]. The opposite argument states that large numbers of species exist although many species have possibly adapted locally; however, their simple morphology prevents discrimination between species e.g. [16,59]. Now that microbes can be identified to species level by using DNA comparisons, as shown for some strains in this study, it is becoming apparent that a large number of freshwater green algal species exists in the world. Some strains in this study matched "brasiliensis" species (Tetranephris, Desmodesmus), and one (GB1a) matched a Fawley's strain collected from the USA. There are therefore still many inconsistencies in patterns of species localization or ubiquity.

\section{Abbreviations}

BLASTN: Basic local alignment search tool for nucleotides; CCAP: Culture collection of algae and protozoa; ITS: Internal transcribed spacer; NIES: National institute for environmental studies (Japan); SAG: The culture collection of algae at Göttingen University; SSU: Small subunit; UTEX: The culture collection of algae, University of Texas.

\section{Competing interests}

The author declares that he has no competing interests.

\section{Acknowledgments}

This work was supported by The Sumitomo Foundation Environmental Research Grant (103180), The Institute for Fermentation, Osaka, and JSPS KAKENHI (25840141)

Received: 11 April 2014 Accepted: 27 August 2014

Published: 2 September 2014

\section{References}

1. Adl SM, Leander BS, Simpson AGB, Archibald JM, Anderson OR, Bass D, Bowser SS, Brugerolle G, Farmer MA, Karpov S, Kolisko M, Lane CE, Lodge DJ, Mann DG, Meisterfeld R, Mendoza L, Moestrup $\varnothing$, Mozley-Standridge SE, Smirnov AV, Spiegel F: Diversity, nomenclature, and taxonomy of protists. Syst Biol 2007, 56:684-689.

2. Achtman $M$, Wagner $M$ : Microbial diversity and the genetic nature of microbial species. Nat Rev Microbiol 2008, 6:431-40.

3. Huss VAR, Sogin ML: Phylogenetic position of some Chlorella species within the chlorococcales based upon complete small-subunit ribosomal RNA sequences. J Mol Evol 1990, 31:432-442.

4. Huss VAR, Frank C, Hartmann EC, Hirmer M, Kloboucek A, Seidel BM, Wenzeler $\mathrm{P}$, Kessler E: Biochemical taxonomy and molecular phylogeny of the genus Chlorella sensu lato (Chlorophyta). J Phycol 1999, 35:587-598.

5. Ustinova I, Krienitz L, Huss VAR: Closteriopsis acicularis (G. M. Smith) Belcher et Swale is a fusiform alga closely related to Chlorella kessleri Fott et Nováková (Chlorophyta, Trebouxiophyceae). Eur J Phycol 2001, 36:341-351.

6. Wolf M, Krienitz L, Hepperle D: Phylogenetic position of Actinastrum hantzschii Lagerheim 1882 (Chlorophyta, Trebouxiophyceae). Algol Stud 2002, 104:59-67.
7. Krienitz L, Hegewald E, Hepperle D, Huss VAR, Rohr T, Wolf M: Phylogenetic relationship of Chlorella and Parachlorella gen. nov. (Chlorophyta, Trebouxiophyceae). Phycologia 2004, 43:529-542.

8. Pröschold T, Bock C, Luo W, Krienitz L: Polyphyletic distribution of bristle formation in Chlorellaceae: Micractinium, Diacanthos, Didymogenes and Hegewaldia gen. nov. (Trebouxiophyceae, Chlorophyta). Phycol Res 2010, 58:1-8.

9. Krienitz L, Bock C, Kotut K, Pröschold T: Genotypic diversity of Dictyosphaerium-morphospecies (Chlorellaceae, Trebouxiophyceae) in African inland waters, including the description of four new genera. Fottea 2012, 12:231-253.

10. Musters W, Boon K, van der Sande CA, van Heerikhuizen H, Planta RJ: Functional analysis of transcribed spacers of yeast ribosomal DNA. EMBO J 1990, 9:2989-2996.

11. Hadjiolova KV, Normann A, Cavaillé J, Soupéne E, Mazan S, Hadjiolov AA, Bachellerie J-P: Processing of truncated mouse or human rRNA transcribed from ribosomal minigenes transfected into mouse cells. Mol Cell Biol 1994, 14:4044-4056.

12. Schultz J, Maisel S, Gerlach D, Muller T, Wolf M: A common core of secondary structure of the internal transcribed spacer 2 (ITS2) throughout the Eukaryota. RNA 2005, 11:361-364.

13. Chen S, Yao H, Han J, Liu C, Song J, Shi L, Zhu Y, Ma X, Gao T, Pang X, Luo K, Li Y, Li X, Jia X, Lin Y, Leon C: Validation of the ITS2 region as a novel DNA barcode for identifying medicinal plant species. PLoS One 2010, 5:e8613.

14. Coleman AW: The significance of a coincidence between evolutionary landmarks found in mating affinity and a DNA sequence. Protist 2000, 151:1-9.

15. Müller T, Philippi N, Dandekar T, Schultz J, Wolf M: Distinguishing species. RNA 2007, 13:1469-1472.

16. Fawley MW, Fawley KP, Buchheim MA: Molecular diversity among communities of freshwater microchlorophytes. Microbial Ecol 2004 48:489-499.

17. Fawley MW, Fawley KP, Owen HA: Diversity and ecology of small coccoid green algae from Lake Itasca, Minnesota, USA, including Meyerella planktonica, gen. et sp. nov. Phycologia 2005, 44:35-48.

18. Lewis LA, Lewis PO: Unearthing the molecular phylodiversity of desert soil green algae (Chlorophyta). Syst Biol 2005, 54:936-947.

19. De Wever A, Leliaert F, Verleyen E, Vanormelingen $P$, Van der Gucht $K$ Hodgson DA, Sabbe K, Vyverman W: Hidden levels of phylodiversity in Antarctic green algae: further evidence for the existence of glacial refugia. Proc $R$ Soc B 2009, 276:3591-3599.

20. Hosoya H, Kimura K, Matsuda S, Kitaura M, Takahashi T, Kosaka T: Symbiotic algae-free strains of the green paramecium Paramecium bursaria produced by herbicide paraquat. Zoo/ Sci 1995, 12:807-810.

21. Ichimura T: Sexual cell division and conjugation-papilla formation in sexual reproduction of Closterium strigosum. In Proceedings of the Seventh International Seaweed Symposium: 1971; Tokyo. Edited by Nishizawa K, Arasaki S, Chihara M, Hirose H, Nakamura V, Tsuchiya Y. 1971:208-214

22. Nakayama T, Watanabe S, Mitsui K, Uchida H, Inouye I: The phylogenetic relationship between the Chlamydomonadales and Chlorococcales inferred from 18S rDNA sequence data. Phycol Res 1996, 44:47-55.

23. Hoshina R, Kato $Y$, Kamako S, Imamura N: Genetic evidence of "American" and "European" type symbiotic algae of Paramecium bursaria Ehrenberg. Plant Biol 2005, 7:526-532.

24. Hoshina R, Kamako S, Imamura N: Phylogenetic position of endosymbiotic green algae in Paramecium bursaria Ehrenberg from Japan. Plant Biol 2004, 6:447-453.

25. White TJ, Bruns T, Lee S, Taylor J: Amplification and direct sequencing of fungal ribosomal RNA genes for phylogenetics. In $P C R$ protocols: a guide to methods and application. Edited by Innis M, Gelfand D, Sninsky J, White T. San Diego: Academic Press; 1990:315-322.

26. Hoshina R: Analysis of an intron intervening the SSU rDNA of Chlorella sp. T-24-5, a photobiont of Paramecium bursaria. Jpn J Protozool 2012, 45:17-27.

27. Hoshina R, Imamura N: Multiple origins of the symbioses in Paramecium bursaria. Protist 2008, 159:53-63.

28. Krienitz L, Bock C, Nozaki H, Wolf M: SSU rRNA gene phylogeny of morphospecies affiliated to the bioassay alga "Selenastrum capricornutum" recovered the polyphyletic origin of crescent-shaped Chlorophyta. J Phycol 2011, 47:880-893. 
29. Marin B: Nested in the Chlorellales or independent class? Phylogeny and classification of the Pedinophyceae (Viridiplantae) revealed by molecular phylogenetic analyses of complete nuclear and plastid-encoded rRNA operons. Protist 2012, 163:778-805.

30. Larkin MA, Blackshields G, Brown NP, Chenna R, McGettigan PA, McWilliam H, Valentin F, Wallace M, Wilm A, Lopez R, Thompson JD, Gibson TJ, Higgins DG: Clustal W and Clustal X version 2.0. Bioinformatics 2007, 23:2947-2948

31. Cannone JJ, Subramanian S, Schnare MN, Collett JR, D'Souza LM, Du Y, Feng B, Lin N, Madabusi LV, Müller KM, Pande N, Shang Z, Yu N, Gutell RR: The Comparative RNA Web (CRW) Site: an online database of comparative sequence and structure information for ribosomal, intron, and other RNAs. BMC Bioinformatics 2002, 3:2.

32. Tamura K, Peterson D, Peterson N, Stecher G, Nei M, Kumar S: MEGA5: Molecular Evolutionary Genetics Analysis using maximum likelihood, evolutionary distance, and maximum parsimony methods. Mol Biol Evol 2011, 28:2731-2739.

33. Posada D, Crandall KA: MODELTEST: testing the model of DNA substitution. Bioinformatics 1998, 14:817-818.

34. Hegewald E, Bock C, Krienitz L: A phylogenetic study on Scenedesmaceae with the description of a new species of Pectinodesmus and the new genera Verrucodesmus and Chodatodesmus (Chlorophyta, Chlorophyceae). Fottea 2013, 13:149-164.

35. Eliáš M, Němcová Y, Škaloud P, Neustupa J, Kaufnerová V, Šejnohová L: Hylodesmus singaporensis gen. et sp. nov., a new autosporic subaerial green alga (Scenedesmaceae, Chlorophyta) from Singapore. Int J Syst Evol Microbiol 2010, 60:1224-1235.

36. Hoshina R, Fujiwara Y: Molecular characterization of Chlorella cultures of the NIES culture collection with description of Micractinium inermum sp. nov., Didymogenes sphaerica sp. nov., and Didymogenes soliella sp. nov. (Chlorellaceae, Trebouxiophyceae). Phycol Res 2013 61:124-132.

37. Zuker M: Mfold web server for nucleic acid folding and hybridization prediction. Nucleic Acids Res 2003, 31:3406-3415.

38. Krienitz L, Ustinova I, Friedl T, Huss VAR: Traditional generic concepts versus $18 \mathrm{~S}$ rRNA gene phylogeny in the green algal family Selenastraceae (Chlorophyceae, Chlorophyta). J Phycol 2001, 37:852-865.

39. Fawley MW, Dean ML, Dimmer SK, Fawley KP: Evaluating the morphospecies concept in the Selenastraceae (Chlorophyceae, Chlorophyta). J Phycol 2005, 42:142-154.

40. Friedl T, O'Kelly CJ: Phylogenetic relationships of green algae assigned to the genus Planophila (Chlorophyta): evidence from 18S rDNA sequence data and ultrastructure. Eur J Phycol 2002, 37:373-384

41. Deason TR, Silva PC, Watanabe S, Floyd GL: Taxonomic status of the species of the green algal genus Neochloris. Pl Syst Evol 1991, 177:213-219.

42. McManus HA, Lewis LA: Molecular phylogenetics, morphological variation and colony-form evolution in the family Hydrodictyaceae (Sphaeropleales, Chlorophyta). Phycologia 2005, 44:582-595.

43. Keller A, Schleicher T, Förster F, Ruderisch B, Dandekar T, Müller T, Wolf M: ITS2 data corroborate a monophyletic chlorophycean DO-group (Sphaeropleales). BMC Evol Biol 2008, 8:218.

44. Fucikova K, Lewis LA: Intersection of Chlorella, Muriella and Bracteacoccus: resurrecting the genus Chromochloris KOL et CHODAT (Chlorophyceae, Chlorophyta). Fottea 2012, 12:83-93.

45. Markert SM, Müller T, Koetschan C, Friedl T, Wolf M: ' $Y$ ' Scenedesmus (Chlorophyta, Chlorophyceae): the internal transcribed spacer 2 rRNA secondary structure re-revisited. Plant Biol 2012, 14:987-996.

46. Booton GC, Floyd GL, Fuerst PA: Multiple group I introns detected in the nuclear small subunit rDNA of the autosporic green alga Selenastrum capricornutum. Curr Genet 2004, 46:228-234.

47. Hegewald E, Wolf M, Keller A, Friedl T, Krienitz L: ITS2 sequence-structure phylogeny in the Scenedesmaceae with special reference to Coelastrum (Chlorophyta, Chlorophyceae), including the new genera Comasiella and Pectinodesmus. Phycologia 2010, 49:325-335

48. Johnson JL, Fawley MW, Fawley KP: The diversity of Scenedesmus and Desmodesmus (Chlorophyceae) in Itasca State Park, Minnesota, USA. Phycologia 2007, 46:214-229.

49. Fawley MW, Fawley KP, Hegewald E: Taxonomy of Desmodesmus serratus (Chlorophyceae, Chlorophyta) and related taxa on the basis of morphological and DNA sequence data. Phycologia 2011, 50:23-56.
50. Fawley MW, Fawley KP, Hegewald E: Desmodesmus baconii (Chlorophyta), a new species with double rows of arcuate spines. Phycologia 2013, 52:565-572.

51. Krienitz L, Bock C: Present state of the systematics of planktonic coccoid green algae of inland waters. Hydrobiologia 2012, 698:295-326.

52. Luo W, Pflugmacher S, Pröschold T, Walz N, Krienitz L: Genotype versus phenotype variability in Chlorella and Micractinium (Chlorophyta, Trebouxiophyceae). Protist 2006, 157:315-333.

53. Bock C, Pröschold T, Krienitz L: Two new Dictyosphaerium-morphotype lineages of the Chlorellaceae (Trebouxiophyceae): Heynigia gen. nov. and Hindakia gen. nov. Eur J Phycol 2010, 45:267-277.

54. Bock C, Krienitz L, Pröschold T: Taxonomic reassessment of the genus Chlorella (Trebouxiophyceae) using molecular signatures (barcodes), including description of seven new species. Fottea 2011, 11:293-312.

55. Bock C, Pröschold T, Krienitz L: Updating the genus Dictyosphaerium and description of Mucidosphaerium gen. nov. (Trebouxiophyceae) based on morphological and molecular data. J Phycol 2011, 47:638-652.

56. Luo W, Pröschold T, Bock C, Krienitz L: Generic concept in Chlorella-related coccoid green algae (Chlorophyta, Trebouxiophyceae). Plant Biol 2010, 12:545-553.

57. Hoshina R, Iwataki M, Imamura N: Chlorella variabilis and Micractinium reisseri sp. nov. (Chlorellaceae, Trebouxiophyceae): Redescription of the endosymbiotic green algae of Paramecium bursaria (Peniculia, Oligohymenophorea) in the 120th year. Phycol Res 2010, 58:188-201.

58. Finlay BJ: Global dispersal of free-living microbial eukaryote species. Science 2002, 296:1061-1063.

59. Coleman AW: Microbial eukaryote species. Science 2002, 297:337.

doi:10.1186/1756-0500-7-592

Cite this article as: Hoshina: DNA analyses of a private collection of microbial green algae contribute to a better understanding of microbial diversity. BMC Research Notes 2014 7:592.

\section{Submit your next manuscript to BioMed Central and take full advantage of:}

- Convenient online submission

- Thorough peer review

- No space constraints or color figure charges

- Immediate publication on acceptance

- Inclusion in PubMed, CAS, Scopus and Google Scholar

- Research which is freely available for redistribution 